\title{
FUNDAMENTAÇ̃̃O TEÓRICA DA EDUCACূ̃̃O FÍSICA EM PROPOSTAS CURRICULARES DA ESCOLA PÚBLICA DE SÃO PAULO: UMA ANÁLISE DAS ABORDAGENS PEDAGÓGICAS
}

\author{
DANIEL TEIXEIRA MALDONADO ${ }^{*}$ \\ ORCID: https://orcid.org/0000-0002-0420-6490 \\ SHEILA APARECIDA PEREIRA DOS SANTOS SILVA ${ }^{2 * *}$ \\ ORCID: https://orcid.org/0000-0001-8205-3146
}

RESUMO: O objetivo desse estudo foi analisar as orientações curriculares da Educação Física (EF) na rede municipal e estadual de São Paulo com vistas a identificar as concepções teóricas que influenciaram sua elaboração. Foram analisadas quatro propostas curriculares da rede estadual e seis documentos oficiais curriculares da rede municipal publicados entre o final da década de 1970 e o ano de 2017. Essa análise mostrou que houve publicações de orientações curriculares durante todo o período pesquisado e que é permanente a intenção de influenciar a prática pedagógica do professor de EF. No entanto, foram notadas mudanças bruscas na forma como era proposto o ensino no interior da escola. Ficou claro que a tematização das manifestações da cultura corporal de movimento se tornou o objetivo hegemônico nas orientações curriculares publicadas na última década, de modo a caracterizar uma superação do paradigma da aptidão física como norteador da prática pedagógica.

Palavras chave: Educação Física Escolar; Currículo; São Paulo.

\section{PHYSICAL EDUCATION'S THEORETICAL BACKGROUND IN CURRICULAR PROPOSALS AT PUBLIC SCHOOLS IN SÃO PAULO: AN ANALYSIS OF PEDAGOGICAL APPROACHES}

ABSTRACT: The goal of this study was to analyse the curricular guidance of Physical Education (PE) in city and state public school networks in São Paulo, in order to identify the theoretical background that influenced its formulation. Were analyzed four curricular proposals of the state's network and six official curricular documents of the city's network, published between the end of the 1970's and the year of 2017. This analysis has shown that curricular guidance documents have been published during the whole

\footnotetext{
${ }^{1}$ Universidade São Judas Tadeu, São Paulo, SP, Brasil.

${ }^{2}$ Pontifícia Universidade Católica de São Paulo, São Paulo, SP, Brasil.

"Doutor em Educação Física pela Universidade São Judas Tadeu. Docente do Instituto Federal de Educação, Ciência e Tecnologia de São Paulo. E-mail:<danieltmaldonado@yahoo.com.br > .

"* Doutora em Educação pela PUC. Docente do Centro Universitário FIEO (UNIFIEO).

E-mail:<sheila.silva@uol.com.br >.
} 
researched period and that the intention of influencing the pedagogical practice of PE teachers is permanent. However, abrupt changes on how to teach PE inside the school were noticed. It was clear that the thematization of body movement culture's manifestations became the hegemonic goal in curricular orientations published in the last decade, characterizing the overcoming of physical fitness as pedagogical practice's guidance.

Keywords: School Physical Education; Curriculum; São Paulo.

\section{INTRODUÇÃO}

A elaboração e a implementação curriculares na educação pública brasileira possuem peculiaridades. Governos, partidos no poder, equipes técnicas se alternam e, em geral, cada um se preocupa em "deixar sua marca" e "dar o seu tom" aos programas e políticas públicas. $\mathrm{Na}$ melhor das hipóteses, quem assume o governo se sente no compromisso de concretizar filosofias partidárias ou convicções de trabalho que foram comunicadas ao público por meio de promessas feitas em tempos de campanha política.

$\mathrm{Na}$ EF escolar brasileira esse fenômeno tem sido bastante evidente. Muitas propostas pedagógicas foram elaboradas visando a orientar as ações didáticas do professor de EF.

Entre o final do século XX e o início do século XXI, se tornaram conhecidas diferentes concepções pedagógicas, cujos focos eram: aprimorar o desenvolvimento motor e psicomotor dos estudantes (FREIRE, 1989; LE BOULCH, 1983; TANI et al., 1988); refletir sobre aspectos conceituais relacionados à saúde e ampliar o nível de atividade física dos alunos (GUEDES, 1999); desenvolver o pensamento crítico dos discentes sobre as manifestações da cultura corporal (COLETIVO DE AUTORES, 1992; KUNZ, 1994); e reconstruir criticamente as práticas corporais, problematizar os discursos sobre elas e seus representantes e promover o diálogo com as diferenças (NEIRA; NUNES, 2009).

Nesse período, que cobre cerca de 40 anos, pesquisadores da área de EF produziram diversas análises sobre essas diferentes concepções pedagógicas (DARIDO; SANCHES NETO, 2008; NEIRA; NUNES, 2008; SILVA, 2013), problematizando e refletindo sobre as teorias que embasavam essas propostas, ao mesmo tempo em que davam pistas aos docentes que trabalhavam em escolas sobre como organizar o seu trabalho pedagógico apoiados na construção teórica da área.

González e Fraga (2012) mencionam que essa variedade de propostas pedagógicas influenciou diretamente a redação de textos legais e propostas oficiais como a Lei de Diretrizes e Bases da Educação Nacional (LDB n ${ }^{\circ}$ 9.346/96), que manifesta a obrigatoriedade da EF 
como componente curricular da Educação Básica, os Parâmetros Curriculares Nacionais da EF, as propostas curriculares de diferentes redes de ensino municipais e estaduais e na consolidação da cultura corporal como objeto de estudo central do componente curricular em todos os ciclos da escolarização.

Em São Paulo, seja na cidade, ou no estado, foram elaboradas diferentes propostas curriculares para subsidiar a prática pedagógica dos docentes de EF que lecionavam em escolas públicas (MALDONADO, 2016). Nesse contexto, esse estudo possui como objetivo analisar as orientações curriculares da EF publicadas entre o final da década de 1970 e o ano de 2017 nas redes municipal e estadual de São Paulo, com vistas a identificar as concepções teóricas que influenciaram sua elaboração.

\section{MÉTODO}

Foram analisadas quatro propostas curriculares de EF da rede estadual, publicadas nos anos de 1978, 1991, 1996 e 2008, e seis documentos oficiais curriculares de EF da rede municipal apresentados aos docentes nos anos de 1976, 1988, 1992, 2006, 2016 e 2017.

Tais documentos foram encontrados nos sites das Secretarias de Educação das respectivas redes e/ou na biblioteca da Secretaria Municipal de Educação de São Paulo, que possui um acervo, muito grande e digitalizado, de referências que versam sobre a educação paulista.

Todos os documentos passaram por análise de conteúdo para identificar como as concepções teóricas da EF influenciaram na elaboração desses currículos.

As categorias de análise utilizadas foram:

a) conteúdos que deveriam ser ensinados;

b) estratégias didáticas a utilizar, e

c) referências bibliográficas citadas nos documentos.

Nem todas as propostas expressavam, claramente, estas categorias. Diante disso, o esforço realizado centrou-se nas que estivessem disponíveis visando compreender cada proposta curricular.

Com base nesta análise, foi descrito um perfil para cada proposta curricular, que constitui os resultados deste artigo.

\section{RESULTADOS E DISCUSSÃO}

\section{PROPOSTAS CURRICULARES DE EF DA REDE ESTADUAL DE SÃO PAULO.}

Em 1978, o estado de São Paulo publica os subsídios para a implementação do guia curricular de EF para o antigo $1^{\circ}$ grau, hoje 
séries iniciais do Ensino Fundamental. O objetivo desse guia curricular foi subsidiar a prática pedagógica dos professores polivalentes que ensinavam EF na escola.

Os docentes tinham que proporcionar aos alunos atividades práticas que os levassem a conhecer o seu próprio corpo de maneira global; desenvolver a orientação e a estruturação espaço-temporal e a coordenação motora; adquirir as capacidades físicas básicas: força, velocidade, resistência e flexibilidade; apresentar hábitos sadios; participar, cooperar e relacionar-se nas diferentes situações de grupos e expressar-se pelo movimento. Tal guia curricular continha diversas atividades práticas que os docentes poderiam realizar para que os seus alunos alcançassem os objetivos propostos (SÃO PAULO, 1978).

Pode-se observar nos objetivos propostos que as aulas eram pautadas pelo paradigma do desenvolvimento da aptidão física dos alunos e no desenvolvimento das habilidades motoras, sendo possível observar certa influência da psicomotricidade nos objetivos propostos, que continuaria, nas décadas seguintes, a influenciar a prática pedagógica dos docentes de EF.

Em 1986, é lançada uma versão preliminar do que viria a ser a Proposta Curricular de EF para o ensino de $1^{\circ}$ Grau, publicada em 1991 como uma $4^{a}$ versão da anterior. Tal proposta criticava a prática pedagógica mecanicista que permeava as aulas de EF na escola. Afirmava que os docentes que ensinavam dessa forma não consideravam as crianças como seres pensantes, desprezavam os conhecimentos que elas já possuíam, impunham valores sociais e culturais distantes da sua realidade e cobravam o rendimento máximo do aluno (SÃO PAULO, 1991).

Era apresentada aos professores uma visão pautada na teoria construtivista-interacionista. $\mathrm{Na}$ visão construtivista, o aluno deve construir o seu conhecimento a partir da sua relação com o mundo, em uma relação que extrapola a prática de ensinar e aprender. O professor de EF deveria respeitar as condições concretas do aluno, ter conhecimento do desenvolvimento da criança relacionado aos esquemas de elaboração mental e respeitar a sua individualidade. Nesse modo de entender a EF, o discente atuava como agente criador e transformador do próprio conhecimento, construindo seu saber (SÃO PAULO, 1991).

Recomendava-se utilizar atividades lúdicas para efetivar a prática pedagógica em EF, pois elas atenderiam às necessidades sociais e afetivas das crianças, e promoveriam o desenvolvimento psicomotor. Essa proposta oferecia aos professores um amplo repertório de brincadeiras e jogos que poderiam ser utilizados durante as aulas (SÃO PAULO, 1991). 
Apesar de ser nítida a relação dessa proposta curricular com as ideias do professor João Batista Freire, que se preocupava com o resgate da cultura popular e se embasava nos autores da Psicologia e com as ideias desenvolvidas pela psicomotricidade mencionadas por Bracht (1999), também constam nas referências bibliográficas utilizadas pelos elaboradores da proposta livros que traziam um olhar crítico para a prática educativa como Educação como prática de liberdade, de Paulo Freire; A Educação Física cuida do corpo... e mente, de João Paulo Subirá Medina; Educação Física Humanista, de Vitor Marinho Oliveira; e Escola e democracia: teorias da educação, curvatura da vara, onze teses sobre educação e política, de Demerval Saviani.

Ainda que a proposta curricular da rede estadual paulista publicada em 1991 estivesse claramente embasada em uma proposta psicomotora fundamentada em Le Boulch (1983) e Freire (1989), já são mencionadas as teorias pautadas nas ciências humanas, de caráter crítico.

Em 1996, o Estado de São Paulo iniciou uma proposta de reorientação curricular para todos os componentes curriculares da sua rede de ensino. $\mathrm{Na} E F$, o documento curricular trazia uma metodologia para se trabalhar com os jogos na escola. Esse foi o primeiro tema tratado no material porque os professores de EF consideraram que o jogo poderia contemplar todas as séries/anos desse ciclo de escolarização (SÃO PAULO, 1996).

Para os idealizadores dessa proposta, os docentes de EF deveriam repensar a sua prática pedagógica e evidenciar uma postura educacional que se distanciasse gradativamente daquela na qual o professor apresentava a atividade pronta e acabada, estabelecia regras e movimentos a serem executados e equalizava os estudantes sob um mesmo padrão de rendimento físico (SÃO PAULO, 1996).

Esse material indicava que o professor de EF deveria ensinar jogos de modo a contemplar as capacidades físicas e habilidades motoras, os aspectos cognitivos, tais como a resolução de problemas pelos alunos com a ajuda do professor e o estímulo ao desenvolvimento de aspectos socioafetivos como aprender a cooperar, a competir e a se tornar autônomo.

A proposta também trazia diversas sugestões de jogos e apontava considerações pedagógicas para que o docente pudesse refletir sobre a metodologia utilizada para ensinar aquela atividade (SÃO PAULO, 1996).

Em 1997 foi lançado o volume dois dessa proposta curricular, discutindo, especificamente, a capacidade física "velocidade". O material apontava uma diversidade de atividades motoras que podiam estimular o desenvolvimento da velocidade e a relacionava com os esportes que necessitam do domínio dessa capacidade (SÃO PAULO, 1997). 
Novamente, na reorientação curricular iniciada em 1997, o jogo aparece como conteúdo central das aulas de EF, e expressava o entendimento que a criança devia ser considerada um ser integral, e desenvolver seus aspectos motores, físicos, cognitivos e afetivos por meio dos conteúdos aprendidos. Essa proposta curricular possui influências desenvolvimentistas (TANI et al. 1988) e da psicomotricidade (FREIRE, 1989, LE BOULCH, 1983). Nela, não conseguimos identificar traços das abordagens críticas bem como nenhuma menção à expressão "cultura corporal" ou "cultura corporal de movimento".

Em 2008, o estado de São Paulo publicou a diretriz curricular que vigora em suas escolas atualmente. Nessa proposta, as aulas de EF escolar deveriam apresentar um enfoque cultural por levar em conta as diferenças manifestadas pelos alunos em variados contextos. Propõe-se que as aulas de EF tratem de maneira pedagógica os conteúdos relacionados ao "Se-Movimentar humano", entendimento fundamentado em Elenor Kunz (1994). Este "Se-Movimentar" se caracteriza como a relação que o sujeito estabelece com a cultura a partir de seu repertório, informações/conhecimentos, movimentos, condutas, entre outras, de sua história de vida, de suas vinculações socioculturais e de seus desejos. Os conteúdos abrangem os jogos, as ginásticas, as danças, as atividades rítmicas, as lutas e os esportes, sempre considerando os processos de significação que dão sentido à realização desses movimentos corporais (SÃO PAULO, 2012).

Para os idealizadores da proposta, os alunos devem vivenciar um amplo conjunto de experiências de movimentos e aprender várias informações e conhecimentos sobre os conteúdos estudados e a EF no ciclo II do Ensino Fundamental transformaria as experiências obtidas nas séries iniciais desse ciclo em eixos de conteúdo.

Dessa maneira, as crianças aprenderiam experiências de saltar nos primeiros cinco anos de frequência à escola e depois seriam levadas a compreender como essas experiências de salto são confrontadas com as modalidades específicas do atletismo como, por exemplo, o salto em distância e o salto em altura. Esse exemplo valeria para todos os outros eixos de conteúdos da EF escolar (SÃO PAULO, 2012).

No Ensino Médio, os cinco eixos de conteúdo - o jogo, o esporte, a luta, a ginástica e a atividade rítmica- deveriam se relacionar com eixos temáticos relevantes e atuais na sociedade contemporânea como o Corpo, a Saúde e a Beleza; a Contemporaneidade; as Mídias; o Lazer e o Trabalho.

Tais eixos temáticos permitiriam discussões de cunho crítico nas aulas de EF escolar, como, por exemplo, preconceito racial nos esportes, discriminação contra as pessoas com deficiência que praticam esportes, 
o papel das mídias na construção de padrões de beleza corporal, os vários significados atribuídos ao corpo, a relação entre exercício físico e saúde, o lazer na vida cotidiana, entre outros (SÃO PAULO, 2012).

Foi possível observar, pelas discussões de eixos de conteúdos e eixos temáticos, que os idealizadores da proposta se pautam em teorias que defendem a formação de seres humanos mais críticos, além de possibilitar vivências das manifestações da cultura corporal de movimento. Essas discussões nascem quando se começam a elaborar os currículos críticos da EF, pautados nas teorias das ciências sociais e humanas (BRACHT; GONZÁLEZ, 2014).

Não obstante, exista forte influência dos autores considerados críticos na elaboração da proposta, a divisão pré-estabelecida e obrigatória de conteúdos por série e por bimestre letivo parece evidenciar certa incoerência com o principal objetivo da proposta, ou seja, se um currículo traz como objetivo possibilitar experiências que tornem o aluno um sujeito crítico e participativo na sociedade, ela também deveria considerar o professor como alguém capaz de fazer uma leitura adequada de sua realidade e, com base nela, planejar seu ensino de forma centralizada ou participativa, e distribuir os conteúdos no calendário.

Entretanto, a proposta não concede essa prerrogativa ao docente a quem não é permitido eleger os eixos de conteúdo e os eixos temáticos mais adequados para as suas turmas. Isso o torna, em muitos contextos, mero executor de tarefas pensadas por outras pessoas, sem possibilidade de um exercício crítico e criativo de sua docência.

Outro aspecto que ajudou a enfatizar o "engessamento" da prática pedagógica do professor de EF foi a publicação dos Cadernos do Aluno, já que esse prevê os conteúdos a trabalhar em cada bimestre e em cada série.

Mesmo que o material apresentado seja de boa qualidade e mostre caminhos de como articular diferentes temas, como basquetebol, padrões de beleza, distúrbios alimentares e modos de calcular o Índice de Massa Corporal, a autonomia didática do professor é prejudicada. Caberia perguntar que causalidades levaram a rede estadual de ensino a propor diretrizes curriculares com tais características.

Ainda nesse contexto, encontramos relatos de experiência publicados a respeito da efetivação da prática pedagógica, que julgam que essa organização proposta foi positiva para que o docente organizasse o seu trabalho pedagógico (GUARINON, 2016; OKIMURA-KERR, 2017).

Percebe-se que desde o ano de 2007, a rede estadual de São Paulo aponta que o professor de EF deve desenvolver conteúdos e 
refletir sobre temas que se relacionam com as manifestações da cultura corporal, o que mostra que esse conceito se tornou hegemônico na proposta curricular dessa rede de ensino.

No Quadro 1, a título de síntese, mostraremos os conteúdos propostos por cada documento curricular da rede estadual no período analisado e a abordagem pedagógica que embasava a proposta.

QUADRO 1.Conteúdos e Teorias Pedagógicas das propostas curriculares de $\mathrm{EF}$ da rede estadual paulista.

\begin{tabular}{|c|c|c|}
\hline DATA & CONTEÚDOS & $\begin{array}{l}\text { ABORDAGEM PEDAGÓGICA } \\
\text { MENCIONADA NO DOCUMENTO } \\
\text { ANALISADO }\end{array}$ \\
\hline 1978 & $\begin{array}{l}\text { Capacidades Físicas; Habilidades Motoras; } \\
\text { Conhecimento do Corpo; Estruturação Espaço- } \\
\text { Temporal; Hábitos Sadios; Participação; e } \\
\text { Cooperação. }\end{array}$ & $\begin{array}{l}\text { Desenvolvimentista } \\
\text { Psicomotora }\end{array}$ \\
\hline 1991 & Desenvolvimento Psicomotor. & Psicomotora \\
\hline 1996 & $\begin{array}{l}\text { Capacidades Físicas; Habilidades Motoras; } \\
\text { Resolução de Problemas; Cooperação; e } \\
\text { Competição. }\end{array}$ & $\begin{array}{l}\text { Desenvolvimentista } \\
\text { Psicomotora }\end{array}$ \\
\hline 2008 & $\begin{array}{l}\text { Manifestações da cultura corporal de movimento } \\
\text { (lutas, ginásticas, esportes, atividades rítmicas, } \\
\text { jogos e brincadeiras); Corpo, a Saúde e a Beleza; } \\
\text { Contemporaneidade; Mídias; Lazer e o Trabalho. }\end{array}$ & $\begin{array}{l}\text { Crítico-Superadora } \\
\text { Crítico-Emancipatória }\end{array}$ \\
\hline
\end{tabular}

Fonte: elaborado pelos autores.

PROPOSTAS CURRICULARES DE EF DA REDE MUNICIPAL DE SÃO PAULO.

Durante a história da educação paulistana, o município de São Paulo elaborou algumas propostas curriculares. Em documento datado de 1976, os professores que atuavam na Diretoria de Orientações Técnicas daquela época publicaram planos de aula relacionados com os guias curriculares propostos para a EF, e, desta forma, conseguimos observar as concepções que estavam enraizadas nas aulas da disciplina (SÃO PAULO, 1976).

Em um dos planos analisados, as aulas eram divididas em três partes. Na parte inicial, o objetivo era aquecer a musculatura das crianças, aumentar a sua flexibilidade e provocar aumento na irrigação sanguínea, com a intenção de preparar o corpo para a parte mais intensa da aula. $\mathrm{Na}$ parte principal, os objetivos eram o desenvolvimento e fortalecimento 
muscular e orgânico, o desenvolvimento da coordenação motora, do equilíbrio, bem como a correção da atitude corporal por meio de exercícios de fácil execução, tendo em vista a evolução física e psíquica do aluno. Era ainda dever do professor levar o aluno a conhecer o nível correto de execução das atividades, aceitar suas limitações e tentar realizar as atividades da melhor maneira possível.

Os docentes deveriam se preocupar em desenvolver as habilidades motoras básicas, o esquema corporal, a orientação espaço temporal, a resistência física e o ritmo. $\mathrm{Na}$ fase final (volta à calma), o professor deveria eliminar a agitação provocada no aluno na parte anterior da aula (SÃO PAULO, 1976).

Nesse plano de aula, pautado no guia curricular da EF de 1976, é nítido que o desenvolvimento da aptidão física dos discentes era um dos principais objetivos, mas já são observados traços do currículo desenvolvimentista (TANI et al. 1988) e do currículo psicomotor (FREIRE, 1989, LE BOULCH, 1983.

Em 1988, a Secretaria Municipal de Educação lançou uma proposta que tinha como objetivo mostrar como as aulas de EF deveriam ser realizadas no Ensino Fundamental. Nesse documento, mencionase que professor deveria deixar de tratar o aluno como um simples reprodutor de atividades motoras para que ele adquirisse condições para se tornar um ser humano crítico, capaz de sugerir e ser criativo dentro do âmbito escolar e do contexto social em que vive (SÃO PAULO, 1988).

Ao propor uma aula, o professor precisaria apresentar os objetivos aos alunos e dar oportunidades para que refletissem sobre eles para, em seguida, participar, sugerir regras, bem como outras atividades, explorando variações dentro de um mesmo jogo ou de uma movimentação. Deveria, também, garantir condições de participação em todas as propostas de trabalho a todos os alunos, independentemente de suas características (SÃO PAULO, 1988).

$\mathrm{Na}$ organização do programa, as habilidades deveriam ser divididas em dois grupos: as habilidades básicas e as específicas. As habilidades básicas foram agrupadas de acordo com os padrões fundamentais de movimento (locomoção, estabilização e manipulação), por entender que o desenvolvimento desses padrões é de grande importância para que as crianças adquiram domínio das habilidades motoras (SÃO PAULO, 1988).

Após um trabalho centrado nas habilidades básicas, o programa sugere atividades que envolvem habilidades motoras específicas utilizadas nos esportes pois, conforme argumentam, se respeita a sequência de desenvolvimento motor e o interesse do aluno. 
$\mathrm{Na}$ etapa em que o professor propusesse tais atividades, o aluno já deveria trabalhar com movimentos construídos, como a manchete do voleibol, por exemplo, características das habilidades motoras determinadas culturalmente e teria que participar efetivamente das atividades em grupo (SÃO PAULO, 1988).

Essa proposta estava claramente pautada na abordagem desenvolvimentista (TANI et al., 1988), no qual as crianças pequenas aprendem as habilidades motoras básicas e depois começam a combinar as habilidades motoras e a desenvolver as habilidades específicas dos diferentes esportes.

Em 1989, Paulo Freire assumiu o cargo de secretário municipal de educação e escreveu uma carta aos professores de EF dessa rede. $\mathrm{Na}$ carta, ele defende que a educação como prática de liberdade também deveria acontecer na EF, propõe a não separação entre "cabeça e corpo" durante as práticas corporais, e lembra que as aulas desse componente curricular não deveriam servir para domesticar os corpos das crianças e adolescentes, mas para fazer com que os discentes refletissem sobre as práticas corporais e as praticassem nas aulas com o objetivo de compreender a realidade em que vivem (SÃO PAULO, 1989).

Na gestão de Paulo Freire, foi abolida a prática da realização dos exames médicos prévios à prática de EF na escola.

Em 1990, foi publicado um documento intitulado "O menino popular e a EF". Ele contém uma reflexão sobre o que significava ter EF na escola e justificava a retirada do exame médico nas escolas municipais. $\mathrm{O}$ argumento expressava que não seria necessário realizar o exame médico para frequentar as aulas de EF porque os exercícios realizados nessas aulas não deveriam ser extenuantes, pois isso seria pedagogicamente inadequado.

Também foi mencionado pelos docentes de EF que participaram dos debates em que o documento foi escrito que o objetivo da aula dessa disciplina dentro da escola necessitaria ter um trabalho que ensinasse todos os alunos, não tendo como função a formação de atletas.

Recomendava-se que a competição dentro da escola deveria estar relacionada à alegria de participar e não apenas à alegria da vitória. Nessa proposta, a presença do professor de EF nos conselhos de classe era necessária e ele avaliaria os seus alunos em conjunto com os demais docentes. Em vista disso, esse professor precisaria ter condições adequadas de trabalho e ser reconhecido como qualquer outro docente (SÃO PAULO, 1990).

Em 1992, o município publicou a visão de área de todos os componentes curriculares. O movimento de reorientação curricular 
nessa ocasião foi realizado em três momentos: problematização, organização dos dados problematizados e devolução das informações para as escolas (SÃO PAULO, 1992).

A elaboração desse documento foi marcada por alguns princípios básicos, como a autonomia da escola, o resgate de práticas e experiências avançadas, a discussão coletiva e a unidade ação-reflexão-ação.

A visão de área de $\mathrm{EF}$ afirmava que seu objeto de conhecimento era constituído pelas manifestações que compunham a cultura corporal, que se materializava nos jogos, esportes, danças, ginásticas, lutas e outras práticas corporais.

Nessa visão, a especificidade da EF era o movimento humano como expressão de uma cultura viva, ou seja, não o movimento que se restringe aos limites orgânicos e biológicos, mas aquele que é fato e fator de cultura, pois possui sentido/significado histórico/antropológico determinado pela própria natureza do ser humano e pelos fatores culturais presentes na forma de movimento (SÃO PAULO, 1992).

Nessa proposta, entendia-se que o docente de EF, não poderia construir a sua prática pela lógica da aptidão física, mas que conduzisse à percepção das práticas corporais como componente cultural de um povo. A prática pedagógica dos professores precisaria fornecer elementos para realizar reflexões críticas em torno das práticas corporais ainda dominantes na EF brasileira, de modo a se tornar transformadora (SÃO PAULO, 1992).

Essa proposta curricular possui forte relação com as discussões dos currículos críticos em EF. Pensamos que não poderia ser diferente, já que Paulo Freire era o Secretário Municipal de Educação e suas ideias influenciaram muitos professores de EF que construíram propostas de ensino. Isso se evidencia, por exemplo, nos livros Metodologia de Ensino da EF (COLETIVO DE AUTORES, 1992) e Transformação Didático-Pedagógica do Esporte (KUNZ, 1994) e tais livros continuam a ser fontes de referência para o estabelecimento de propostas pedagógicas e para a atuação didática em EF.

Nesse sentido, as discussões sobre as manifestações da cultura corporal começaram a aparecer no currículo oficial dessa rede de ensino e a visão disseminada sobre o papel do professor de EF muda. Ele deixa de ser entendido como aquele que ensina apenas as habilidades motoras básicas e específicas para os seus alunos e passa a ser o professor que ensina as danças, as ginásticas, as lutas, os jogos, as brincadeiras e os esportes com o propósito de estabelecer, durante as aulas, relações reflexivas com a realidade em que o aluno vive e em que ele ministra aula, com o objetivo de ampliar a consciência crítica dos estudantes. 
Em 2006, a prefeitura de São Paulo lançou um documento referencial de expectativas para o desenvolvimento da competência leitora e escritora no ciclo II do Ensino Fundamental. A EF, como componente curricular obrigatório da Educação Básica, poderia ajudar no desenvolvimento dessa competência, já que era uma responsabilidade de toda a escola (SÃO PAULO, 2006). Para isso, os professores precisariam utilizar uma variedade de textos para ensinar os conteúdos da sua área (contos, poemas, propagandas, informes científicos, pesquisas e relatos históricos, biografias, gráficos, tabelas, imagens, etc.), sem deixar de lado os objetivos específicos de área de EF para cada ano escolar (SÃO PAULO, 2006).

Especificamente na EF, o movimento humano passou a ser entendido como linguagem, pois o ser humano, ao realizar movimentos, expressa uma intencionalidade. Assim, o movimento humano é concebido como forma de expressar sentimentos, sensações, emoções e toda a produção cultural da humanidade (SÃO PAULO, 2006).

Nessa proposta, a cultura corporal era compreendida como esporte, ginástica, danças, lutas, brincadeiras e outras manifestações culturais e considerada um campo de luta que expressa a intencionalidade comunicativa do movimento humano. Esse entendimento foi exemplificado por meio da capoeira, uma manifestação corporal anteriormente malvista pela sociedade e praticada por uma pequena parcela da população, na qual seus praticantes chegaram a ser presos e os seus gestos eram tidos como violentos. Atualmente, a capoeira e os capoeiristas são vistos de outra forma na sociedade e essa prática corporal está inserida na escola (SÃO PAULO, 2006).

Nessa ótica da abordagem cultural, o objetivo da EF é propiciar aos estudantes a oportunidade de conhecer seu próprio repertório de cultura corporal com maior profundidade, ampliando-o e compreendendo-o, como também acessar alguns códigos de comunicação por meio das diferentes manifestações corporais. A competência leitora deveria ser desenvolvida nas aulas de EF por meio da leitura e interpretação do gesto, do movimento humano, do signo cultural constituinte dos diversos grupos que compõem a sociedade contemporânea (SÃO PAULO, 2006).

Em 2007, a prefeitura de São Paulo oficializa essa proposta curricular lançada em 2006, mantendo a visão de mundo, ser humano e sociedade. Nesse contexto, as aulas de EF escolar deveriam ser pautadas na metáfora do corpo cidadão, ou seja, os movimentos deveriam ser realizados como expressão de intencionalidade e da maneira de compreender o mundo. 
As aulas de EF teriam que garantir aos estudantes o acesso ao patrimônio da cultura corporal acumulado historicamente, por meio da experimentação das variadas formas como esses movimentos estavam inseridos na sociedade. Ao trabalhar os diferentes conteúdos da EF, propunha-se realizar, com os estudantes, análises dos motivos que levaram a sociedade a requisitar e valorizar mais determinados conhecimentos do que outros e propunha refletir sobre informações veiculadas pelos meios de comunicação de massa e sobre os saberes da motricidade humana produzidos pelos grupos culturais desprivilegiados na escola (SÃO PAULO, 2007).

Os Estudos Culturais e o Multiculturalismo Crítico constavam como principal referência teórica e foi denominada como abordagem cultural da EF.

Muitos relatos de experiência de docentes de EF que buscavam seguir essas diretrizes curriculares foram publicados em anos subsequentes à sua implementação nas escolas municipais paulistas, encabeçados por docentes da Faculdade de Educação da Universidade de São Paulo e servidores efetivos da equipe técnica da Secretaria Municipal de Educação (NEIRA; LIMA; NUNES, 2012; NEIRA; NUNES; LIMA, 2014; NEIRA, 2017).

Em 2013, iniciou-se um processo de reestruturação curricular que culminou com a publicação de uma nova proposta em 2016. Esta se apoiava em uma perspectiva crítica e emancipadora que trazia a qualidade social da educação como elemento central. O texto curricular apresentava como pilar a intenção de fazer da escola um espaço público que privilegiasse a superação de desigualdades, reconhecesse as relações de poder que hierarquizam as diferenças, possibilitasse o desenvolvimento do pensamento crítico e principalmente, que fosse capaz de promover uma educação comprometida com a transformação da realidade (SÃO PAULO, 2016).

Nessa perspectiva, a EF continua a ser vista como linguagem, porque ao praticar as diferentes manifestações da cultura corporal de movimento, os seres humanos se comunicam e transformam o movimento em linguagem. Cada grupo cultural cria e recria seu estilo próprio, expressa sua cultura por meio dessas práticas e elabora, por meio de infinitas transformações, novos códigos de comunicação.

A proposta se estruturou com suportes teóricos da Filosofia, da Sociologia e da Antropologia, rompendo uma tradição da área que, frequentemente, se utilizou de concepções biológicas e psicológicas para produzir seus currículos (SÃO PAULO, 2016). 
Para justificar a necessidade de um estudo reflexivo no interior das aulas de EF sob a ótica das ciências humanas, foram mencionadas a desigualdade social, questões de classe, gênero, etnia, sexualidade, gerações, dentre outras questões que constituem a cultura como um campo de conflitos e contribuem para que os jovens utilizem o seu corpo e diferentes gestos para marcar sua posição (SÃO PAULO, 2016).

A prática pedagógica dos professores de EF deveria se pautar na "descolonização dos currículos" e impedir que as práticas corporais europeias e estadunidenses dominassem as aulas. Problematizar permanentemente os elementos históricos, políticos, econômicos e culturais que produziam era uma necessidade. Acreditava-se, assim, que as práticas condicionariam e determinariam a construção, a permanência e a transformação das manifestações da cultura corporal e valorizariam os conhecimentos dos estudantes sobre as diferentes práticas corporais tematizadas durante as aulas (SÃO PAULO, 2016).

Percebe-se, ao longo das análises documentais realizadas, que as propostas passam a ser redigidas com fundamentação teórica mais extensa que as anteriores e com itens de sistematização curricular, como os eixos curriculares, mais explícitos.

Essa proposta para o ensino da EF se estrutura em quatro eixos que serão descritos a seguir.

O eixo denominado Acesso às manifestações da cultura corporal visa possibilitar aos estudantes entrar em contato com as inúmeras produções culturais vinculadas às brincadeiras, aos esportes, às danças, às ginásticas, e a todas as práticas corporais por meio de vivências, de estudos e de pesquisas.

O eixo denominado Interpretação dos significados atribuidos àspráticas corporais, prevê que os estudantes analisem, reflitam, interpretem, infiram, pesquisem, classifiquem, ajam, apreciem e relacionem as diferentes formas de praticar as múltiplas manifestações da cultura corporal e os diferentes discursos que as validam ou invalidam.

Já o eixo denominado Problematização das relações de poder presentes nas manifestações da cultura corporal propõe desnaturalizar as hierarquias que marcam as pessoas, por exemplo, pensar que o futebol não deve ser praticado por meninas ou que a dança não deve ser praticada por meninos.

O quarto eixo, denominado Ressignificação e criação, visa estimular os estudantes a ressignificarem as práticas corporais estudadas, vivenciadas, pesquisadas, de modo a realizar adaptações de acordo com seus interesses e desejos (SÃO PAULO, 2016).

Ao analisar a proposta, parece claro que essa orientação curricular em EF se configura com elementos das teorias críticas 
da educação presentes no livro Metodologia do Ensino na EF (COLETIVO DE AUTORES, 1992) e das teorias pós-críticas da educação que já embasavam a orientação curricular anterior, e que na EF são conhecidas, por exemplo, por meio dos livros Educação Física, Currículo e Cultura (NEIRA; NUNES, 2009) e Pedagogia da Cultura Corporal: críticas e alternativas (NEIRA; NUNES, 2008).

No ano de 2017 se inicia uma nova gestão na Prefeitura de São Paulo e, em menos de um ano, esse grupo gestor lança uma nova proposta curricular, que foi intitulada como "Currículo da Cidade" (SÃO PAULO, 2017; SÃO PAULO, 2018).

Nessa proposta, a EF continua inserida na área de Linguagens, junto com Artes, Língua Inglesa e Língua Portuguesa. O documento foi organizado para que os temas da cultura corporal fossem trabalhados entre o $1^{\circ}$ e o $9^{\circ}$ ano do Ensino Fundamental, com objetos do conhecimento organizados em três ciclos: alfabetização, interdisciplinar e autoral (SÃO PAULO, 2017).

O ensino possuía como objetivo tematizar as práticas corporais, concebendo-as como um conjunto de práticas sociais centradas no movimento. Para selecionar as práticas corporais a serem tematizadas com os estudantes, o professor precisaria utilizar critérios como: relevância social e cultural, relevância para a formação intelectual do estudante, potencialidade do estabelecimento de conexões interdisciplinares e contextualização e acessibilidade e adequação aos interesses da faixa etária (SÃO PAULO, 2017).

Os direitos de aprendizagem da EF contidos nessa diretriz curricular se relacionam com os eixos temáticos da cultura corporal: jogos/brincadeiras, lutas, esportes, danças, ginásticas, práticas corporais de aventura (SÃO PAULO, 2017).

No ciclo de alfabetização contemplam-se as brincadeiras e jogos, os esportes de marca, precisão e invasão; a ginástica geral; as danças; as lutas/jogos de oposição; as práticas corporais de aventura urbanas e da natureza, sempre com abrangência relativa aos contextos familiar e comunitário (SÃO PAULO, 2017).

Durante o ciclo interdisciplinar, amplia-se a abrangência do trato com os objetos de conhecimento e eles passam a ser tematizados nos contextos regional e nacional, restritos ao Brasil. Os objetos de conhecimento são as brincadeiras e jogos regionais e populares; os esportes de campo e taco, rede e parede, de invasão e técnicocombinatório; a ginástica geral com práticas corporais circenses e ginásticas de condicionamento; as danças; as lutas; práticas corporais de aventura urbanas e da natureza (SÃO PAULO, 2017). 
Por fim, no ciclo autoral, os objetos de conhecimento são tratados nos contextos mundial e digital e incluem, além dos já citados no ciclo anterior, a ginástica de consciência corporal e as danças urbanas brasileiras (SÃ O PAULO, 2017).

Para atingir os objetivos de aprendizagem de cada eixo temático, ano/série do Ensino Fundamental, o professor necessitaria propor atividades de ensino diversificadas, como pesquisas, testes, entrevistas, análise de vídeos, passeios para museus, pistas, espetáculos, caminhadas no bairro, dentre outras, utilizando assim, diferentes espaços da escola, da comunidade e da cidade (SÃO PAULO, 2018).

Os conteúdos deveriam ser trabalhados nas dimensões: conceitual, atitudinal e procedimental, ou seja, além de vivenciar diversificadas práticas corporais, os discentes precisariam refletir, por exemplo, sobre os hábitos alimentares, a aparência, a sexualidade e reprodução, o consumo de drogas, o papel do esporte, o repouso, as atividades de lazer ou os padrões de beleza e saúde corporal impostos pela mídia e pelo contexto ideológico (SÃO PAULO, 2018).

Com tais características, nos parece claro o embasamento da proposta nas abordagens críticas da EF, junto a aspectos presentes nos Parâmetros Curriculares Nacionais da EF (BRASIL, 1997; 1998) como a recomendação de tratar os conteúdos nas dimensões conceituais, atitudinais e de procedimentos.

Além disso, essa proposta foi criada levando em consideração a matriz didático-pedagógica e segue os princípios didáticos contidos na Base Nacional Comum Curricular do Ensino Fundamental (BRASIL, 2017).

Portanto, desde 1992, os currículos oficiais deEF na rede municipal deSão Paulo compreendem que o docente necessita desenvolver reflexões, debates e vivências relacionadas com as manifestações da cultura corporal com os estudantes. Ao menos na redação das propostas, os objetivos das aulas deixam de focalizar o desenvolvimento do repertório motor e da aptidão física dos discentes e se voltam para a oferta de possibilidades de experiências de danças, ginásticas, lutas, jogos, brincadeiras e esportes aos alunos com vistas à ampliação da compreensão dos aspectos culturais inerentes a essas práticas corporais.

No Quadro 2, a título de síntese, mostramos os conteúdos propostos por cada documento curricular da rede municipal no período analisado e a abordagem pedagógica que embasava a proposta. 
QUADRO 2. Conteúdos e Teorias Pedagógicas das propostas curriculares de EF publicadas na rede municipal de São Paulo.

\begin{tabular}{|c|c|c|}
\hline DATA & CONTEÚDOS & $\begin{array}{l}\text { ABORDAGEM PEDAGÓGICA } \\
\text { MENCIONADA NO DOCUMENTO } \\
\text { ANALISADO }\end{array}$ \\
\hline 1976 & $\begin{array}{l}\text { Capacidades Físicas; Habilidades Motoras; } \\
\text { Estruturação Espaço-Temporal; Ritmo. }\end{array}$ & $\begin{array}{l}\text { Desenvolvimentista } \\
\text { Psicomotora }\end{array}$ \\
\hline 1988 & Habilidades Motoras & Desenvolvimentista \\
\hline 1992 & $\begin{array}{l}\text { Cultura Corporal (jogos, ginásticas, danças, } \\
\text { lutas, esportes e outras práticas corporais). }\end{array}$ & $\begin{array}{l}\text { Crítico-Superadora } \\
\text { Crítico-Emancipatória }\end{array}$ \\
\hline 2006 & $\begin{array}{l}\text { Cultura Corporal (jogos, ginásticas, danças, } \\
\text { lutas, esportes e todas as outras manifestações } \\
\text { culturais); Marcadores Sociais (classe social, } \\
\text { gênero, etnia, religião). }\end{array}$ & Cultural \\
\hline 2016 & $\begin{array}{l}\text { Manifestações da cultura corporal de } \\
\text { movimento (lutas, ginásticas, esportes, } \\
\text { atividades rítmicas, jogos e brincadeiras); } \\
\text { Conhecimentos históricos, políticos, } \\
\text { econômicos e culturais sobre as práticas } \\
\text { corporais; Marcadores Sociais (classe } \\
\text { social, gênero, etnia, religião). }\end{array}$ & $\begin{array}{l}\text { Crítico-Superadora } \\
\text { Crítico-Emancipatória } \\
\text { Cultural. }\end{array}$ \\
\hline 2017 & $\begin{array}{l}\text { Manifestações da cultura corporal (jogos/ } \\
\text { brincadeiras, lutas, esportes, danças, } \\
\text { ginásticas e práticas corporais de aventura } \\
\text { no contexto familiar, comunitário, regional, } \\
\text { nacional, mundial e digital). Refletir sobre as } \\
\text { manifestações da cultura corporal a partir } \\
\text { das três dimensões do conteúdo. }\end{array}$ & $\begin{array}{l}\text { Crítico-Superadora } \\
\text { Crítico-Emancipatória } \\
\text { Parâmetros Curriculares } \\
\text { Nacionais } \\
\text { Base Nacional Comum } \\
\text { Curricular }\end{array}$ \\
\hline
\end{tabular}

Fonte: elaborado pelos autores.

\section{CONSIDERAC̣ÕES FINAIS}

Ao analisar e lançar um olhar temporal para as propostas curriculares, foram perceptíveis mudanças na forma como era preconizado o ensino da EF na escola.

A alternância de filosofias educacionais dos diferentes grupos que assumiram o poder e a gestão educacional se refletem nos documentos analisados. Além disso, as fundamentações teóricas 
presentes, de forma mais ou menos explícitas, nas propostas são fruto de uma mudança paradigmática na área da EF escolar na qual se observa um predomínio atual das ciências humanas.

O mesmo não se pode afirmar quando são analisados contextos não escolares, nos quais as ciências biológicas continuam a constituir a base teórica predominante.

Isso chama a atenção para a especificidade da EF escolar que, ainda que não deva se esquecer, tampouco desvalorizar o fato de que todos somos corpos e que nossa saúde não pode prescindir de níveis apropriados de aptidão e condição física, precisa se aproximar dos demais componentes curriculares e com eles compartilhar a tarefa de promover o desenvolvimento integral dos estudantes, com olhar crítico para o mundo.

A tematização das manifestações da cultura corporal de movimento nas aulas de EF escolar são os conteúdos hegemônicos nas propostas curriculares paulistas publicadas na última década, o que exige um olhar atento para as iniciativas de formação continuada, uma vez que há docentes que atuam nessas redes e que foram formados sem essa perspectiva.

O docente, por sua vez, também necessita ter desenvolvido um olhar crítico e para a realidade de modo a ser capaz de compreender seu cotidiano de trabalho, ter atitude propositiva, e estar ciente da importância do seu papel na educação pública brasileira.

\section{REFERÊNCIAS}

BRACHT, V. A constituição das teorias pedagógicas da Educação Física. Cadernos Cedes. Ano XIX, n. 48, p. 69-88, 1999.

BRACHT, V.; GONZÁLEZ, F. J. Educação Física Escolar. In: GONZÁLEZ, F. J.; FESNTERSEIFER, P. E. Dicionário Crítico da Educação Física. $3^{\circ}$ ed. Ijuí: Unijuí, 2014.

BRASIL. Ministério de Educação e do Desporto. Parâmetros Curriculares Nacionais: terceiro e quarto ciclos: Educação Física / Secretaria de Ensino Fundamental. Brasília: $\mathrm{MEC} / \mathrm{SEF}, 1997$.

BRASIL. Secretaria de Educação Fundamental. Parâmetros Curriculares Nacionais: Educação Física. Brasília: MEC/ SEF, 1998.

BRASIL. Ministério da Educação. Base Nacional Comum Curricular: Educação é a Base. Brasília: MEC, 2017. Disponível em <http://basenacionalcomum.mec.gov.br/>. Acesso em: 15 abr. 2017.

COLETIVO DE AUTORES. Metodologia do ensino de Educação Física. São Paulo: Cortez, 1992.

DARIDO, S. C.; SANCHES NETO, L. O contexto da Educação Física na escola. In: DARIDO, S. C.; RANGEL, I. C. A. Educação Física na escola: implicações para a prática pedagógica. Rio de Janeiro: Guanabara Koogan, p. 1-24, 2008. 
FREIRE, J. B. Educação de Corpo Inteiro: teoria e prática da Educação Física. Campinas: Scipione, 1989.

GONZÁLEZ, F. J.; FRAGA, A. B. Afazeres da Educação Física na escola: planejar, ensinar, partilhar. Erechim: Edelbra, 2012.

GUARINON, P. C. Representações sociais e os currículos da Educação Física: com a palavra os alunos. Dissertação (Mestrado em Educação) - Faculdade de Educação Física da Universidade de São Paulo, São Paulo, 2016.

GUEDES, D. P. Educação para saúde mediante programas de Educação Física Escolar. Motriz. Rio Claro, v. 5, n. 1, junho, 1999.

KUNZ, E. Transformação didático-pedagógica do esporte. Ijuí: Unijuí, 1994.

LE BOULCH, J. A educação pelo movimento: a psicocinética na idade escolar. Porto Alegre: Artes Médicas, 1983.

MALDONADO, D. T. Os bastidores da Educação Física na escola pública paulistana: a percepção da realidade cotidiana. Tese (Doutorado). Universidade São Judas Tadeu, São Paulo, 2016.

NEIRA, M. G.; NUNES, M. L. F. Pedagogia da cultura corporal: críticas e alternativas. $2^{\text {a }}$. ed. São Paulo: Phorte, 2008.

NEIRA, M. G.; NUNES, M. L. F. Educação Física, Currículo e Cultura. São Paulo: Phorte, 2009.

NEIRA, M. G. Educação Física Cultural: o currículo em ação. São Paulo: Labrador, 2017.

NEIRA, M. G.; LIMA, M. E.; NUNES, M. L. F. Educação Física e culturas: Ensaios sobre a prática. São Paulo: FEUSP, 2012.

NEIRA, M. G.; NUNES, M. L. F.; LIMA, M. E. Educação Física e culturas: Ensaios sobre a prática. São Paulo: FEUSP, 2014.

OKIMURA-KERR, T. Promoção da saúde e Ensino Médio: possibilidades de intervenção a partir do currículo do Estado de São Paulo. In: OKIMURA-KERR, Tieme; ULASOWICZ, Carla. Educação Física Escolar e Saúde: perspectivas e possibilidades. Curitiba: CRV, p. 119-136. 2017.

SÃO PAULO. SECRETARIA ESTADUAL DA EDUCAÇÃO. Coordenadoria de Estudos e Normas Pedagógicas. Subsídios para a implementação do guia curricular de Educação Física para o $1^{\circ}$ grau $-5^{\mathrm{a}}$ a $8^{\mathrm{a}}$ séries. SE/CENP, 1978.

SÃO PAULO. SECRETARIA ESTADUAL DA EDUCAÇÃO. Educação Física - $\mathbf{1}^{\circ}$ grau: $5^{\circ}$ a $8^{\circ}$ séries. São Paulo: SE/CENP, v. 1, 1996.

SÃO PAULO. SECRETARIA ESTADUAL DA EDUCAÇÃO. Educação Física Ensino Fundamental: $5^{\circ}$ a $8^{\circ}$ séries. $2^{a}$ Ed. São Paulo: SE/CENP, v. 2, 1997.

SÃo PAUlO. SECRETARIA ESTADUAL DA EDUCAÇÃO. Proposta Curricular do Estado de São Paulo: Educação Física Ensino Fundamental e Médio (estudo e ensino). São Paulo: SEE, 2012.

SÃO PAUlO. SECRETARIA MUNiCiPAL DE EDUCAÇÃO. Modelo de desenvolvimento do currículo - Educação Física $-1^{\circ}$ Série: sugestões de atividades 
para os professores trabalharem com os alunos, aula por aula, tem em vista os conteúdos propostos pelos guias curriculares. 1976.

SÃO PAUlO. SECRETARIA MUNICIPAL DE EDUCAÇÃO. Programa e Implementação da Educação Física $-\mathbf{1}^{\mathbf{a}}$ à $\mathbf{8}^{\mathbf{a}}$ série. 1988.

SÃO PAULO. SECRETARIA MUNICIPAL DE EDUCAÇÃO. Carta aos professores de Educação Física - Paulo Freire. 1989.

SÃO PAULO. SECRETARIA MUNICIPAL DE EDUCAÇÃO. O menino popular e a Educação Física. Diretoria de Orientações Técnicas, 1990.

SÃO PAULO. SECRETARIA MUNICIPAL DE EDUCAÇÃO. Educação Física: visão de área. Diretoria de Orientações Técnicas, 1992.

SÃO PAULO. SECRETARIA MUNICIPAL DE EDUCAÇÃO. DIRETORIA DE ORIENTAÇÃO TÉCNICA. Orientações curriculares e proposição de expectativas de aprendizagem para o Ensino Fundamental: Ciclo 2: Educação Física. São Paulo: SME/DOT, 2007.

SÃO PAULO. SECRETARIA MUNICIPAL DE EDUCAÇÃO. DIRETORIA DE ORIENTAÇÃO TÉCNICA. Programa Mais Educação São Paulo: subsídios para a implantação. São Paulo: SME/DOT, 2014.

SÃO PAULO. SECRETARIA MUNICIPAL DE EDUCAÇÃO. DIRETORIA DE ORIENTAÇÃO TÉCNICA. Direitos de Aprendizagem dos ciclos interdisciplinar e autoral: Educação Física. São Paulo: SME/COPED, 2016.

SÃO PAULO. SECRETARIA MUNICIPAL DE EDUCAÇÃO. COORDENADORIA PEDAGÓGICA. Currículo da Cidade: Ensino Fundamental: Educação Física. São Paulo: SME/COPED, 2017.

SÃO PAULO. SECRETARIA MUNICIPAL DE EDUCAÇÃO. COORDENADORIA PEDAGÓGICA. Orientações didáticas do currículo da cidade - Educação Física. São Paulo: SME/COPED, 2018.

SILVA, S. A. P. S. (org.) Portas abertas para a Educação Física: falando sobre abordagens pedagógicas. São Paulo: Phorte, 2013.

TANI, G. et al. Educação Física Escolar: fundamentos de uma abordagem desenvolvimentista. São Paulo: EPU, 1988.

Submetido: $14 / 06 / 2018$

Aprovado: 08/08/2018

Contato:

Instituto Federal de Educação, Ciência e

Tecnologia de São Paulo (IFSP)

Diretoria de Humanidades

Estrada Velha da Penha no 265, Tatuapé

São Paulo $\mid$ SP | Brasil

CEP 03.090-020 